\title{
No evidence for association between DRD3 and COMT with schizophrenia in a Malay population
}

\author{
S.F. Tee ${ }^{1}$, P.Y. Tang ${ }^{2}$ and H.C. Loh ${ }^{1}$ \\ ${ }^{1}$ Department of Chemical Engineering, Faculty of Engineering and Science, \\ Universiti Tunku Abdul Rahman, Kuala Lumpur, Malaysia \\ ${ }^{2}$ Department of Biomedical Engineering, Faculty of Engineering and Science, \\ Universiti Tunku Abdul Rahman, Kuala Lumpur, Malaysia \\ Corresponding author: H.C. Loh \\ E-mail: hcloh@utar.edu.my
}

Genet. Mol. Res. 10 (3): 1850-1855 (2011)

Received January 5, 2011

Accepted April 29, 2011

Published August 26, 2011

DOI http://dx.doi.org/10.4238/vol10-3gmr1237

\begin{abstract}
Molecular components of the dopamine D3 receptor (DRD3) may play an important role in the pathophysiology of schizophrenia. Previous studies have demonstrated an association between DRD3 Ser9Gly and cathechol-o-methyltransferase (COMT, $\mathrm{SNP}=$ rs165656) polymorphisms and schizophrenia but the results were inconclusive. We investigated this apparent association between Ser9Gly (A/G) polymorphism and an intronic SNP (dbSNP or rs165656) in 261 Malay patients diagnosed with schizophrenia and 216 controls, using PCR-RFLP. The genotype distribution of the polymorphism DRD3 Ser9Gly was in Hardy-Weinberg equilibrium (HWE) for patients $(\mathrm{P}=0.1251)$ and out of $\mathrm{HWE}$ for controls $(\mathrm{P}=$ 0.0137). However, both healthy controls and schizophrenia patients were out of HWE for the polymorphism COMT rs165656. Based on allele and genotype frequencies in both groups, we found no significant association of DRD3 Ser9Gly polymorphisms and COMT (rs165656) with schizophrenia in Malays. Further studies should examine the
\end{abstract}


association between other dopamine-related genes and the behavioral phenotypes of schizophrenia.

Key words: Schizophrenia; Polymerase chain reaction; Single nucleotide polymorphism; Dopamine D3 receptor; Restriction fragment length polymorphism;

Cathechol-o-methyltransferase

\section{INTRODUCTION}

Schizophrenia (SCZ) is a common but complex disease with a worldwide lifetime risk of 1\% (Schwab and Wildenauer, 2008). The Burden of Disease Study in 2004 showed that mental disorders contributed $8.6 \%$ to total disability-adjusted life year, making it the 4 th leading cause of disease burden in Malaysia. From 2003 to 2005, a total of 7351 cases of SCZ were registered in Malaysia. Registered cases increased about 216 cases annually, from 2292 to 2508 cases over these three years. With the Malaysian population at 25 million, these numbers represent a very small proportion of the population, indicating that under-reporting cases may occur especially in East Malaysia (National Mental Health Registry Report, 2003-2005).

Dysregulation in the dopaminergic system has been suggested to play an important role in the pathophysiology of SCZ (Utsunomiya et al., 2008). The dopamine D3 receptor (DRD3) is localized to limbic areas of the brain and is involved in the reinforcing effects of emotional, cognitive and endocrine functions. It is thought to be implicated in $\mathrm{SCZ}$ and other neuropsychiatric disorders (Staddon et al., 2005). It is well known that DRD3 may mediate the therapeutic actions of antipsychotic drugs (Suzuki et al., 1998) while cathechol-o-methyltransferase (COMT) regulates the amount of dopamine in the prefrontal cortex. Substantial studies indicate a close relationship between COMT and several human psychotic disorders such as bipolar disorder (Kunugi et al., 1997; Shifman et al., 2004) and mental retardation (Zhang et al., 2007).

The DRD3 gene maps to chromosome 3q13.3 (Le Coniat et al., 1991) and there is a polymorphic site in its first exon that leads to a serine to glycine amino acid substitution at position 9 (Ser9Gly) in the extracellular N-terminal domain of the receptor (Lannfelt et al., 1992). Several case-control studies between the DRD3 Ser9Gly polymorphism and SCZ have been conducted and these studies have yielded variable results. Some studies suggested a significant association between the DRD3 Ser9Gly polymorphism and SCZ (Crocq et al., 1992; Spurlock et al., 1998; Scharfetter et al., 1999; Talkowski et al., 2006), while others did not find any evidence of either excess of homozygosity, or allelic or genotypic association (Durany et al., 1996; Ioannidis et al., 2001; Fathalli et al., 2008). Even several meta-analyses reported that the DRD3 Ser9Gly polymorphism may not confer susceptibility to SCZ (Jonsson et al., 2003, 2004; Utsunomiya et al., 2008).

The COMT gene is located on chromosome $22 \mathrm{q} 11.2$ and harbors two promoters and six exons. These two promoters are responsible for two different transcripts, which encode a membrane bound COMT (MB-COMT) and a soluble COMT (S-COMT) (Tenhunen et al., 1994). MB-COMT is the dominant allozyme in the brain (Chen et al., 2004). A single nucleotide polymorphism (SNP) rs 165656 in the region of intron 4 that is near to exon 5 in the COMT gene is associated with mental retardation, which has a close relationship with psychotic disorders (Zhang et al., 2007). 
With the increase in variable results obtained from studies in both European and Asian populations, there is a need to examine the association between the DRD3 Ser9Gly and COMT rs165656 polymorphisms and SCZ in Malaysia. In the present study, we were interested in the genotyping the Malay population who is the largest ethnic group in Malaysia.

\section{MATERIAL AND METHODS}

This case-control study involved 261 inpatients with SCZ (137 males; 124 females) recruited from Hospital Bahagia, Ulu Kinta, Perak, Malaysia. The patients had a mean age of 46.5 years (SD 13.6). All patients were evaluated using the Mini-International Neuropsychiatric Interview (MINI). Patients with co-mobidity were excluded. A total of 216 volunteer control subjects (116 males; 100 females), with a mean age of 38.4 years (SD 14.2) were recruited from blood donation centers at Universiti Tunku Abdul Rahman and Kuala Lumpur. All controls were free of any psychiatric illness, drug abuse and family history of psychiatric disorders. All participating subjects were unrelated, born in Malaysia and self-identified as being of Malay descent. This study was approved by the Medical Research Ethics Committee, Ministry of Health, Malaysia.

A peripheral blood sample was obtained from each subject. Genomic DNA was prepared using the Wizard DNA Isolation Kit (Promega, WI, USA). The distribution of the DRD3 Ser9Gly and COMT rs165656 polymorphisms was determined by polymerase chain reaction-restriction fragment length polymorphism (PCR-RFLP) analysis. Amplification of DRD3 Ser9Gly was performed with the following primers: 5'-GCTCATCTCCAACTCTCACA-3' and 5'-AAGTCTACTCACCTCGTA-3' (Ebstein et al., 1997). The PCR products were then digested with $5 \mathrm{U}$ MscI. Meanwhile, amplification of COMT rs165656 was performed with the following primers: 5'-GTCATCGCCAGGTTAGGG-3' and 5'-TGAGGACACCAGGCTTCT-3'. The PCR products were digested with 2.5 U HaeIII. DNA fragments were visualized on $2.5 \%$ agarose gel and $10 \%$ polyacryamide gel electrophoresis and stained with ethidium bromide.

The fitness of genotype frequency distribution to the Hardy-Weinberg equilibrium (HWE) was tested using Arlequin version 3.11 (http://anthro.unige.ch/arlequin). Allelic and genotype frequency differences between patients and controls were analyzed using the chisquare $\left(\chi^{2}\right)$ test of the Statistical Package for the Social Sciences, version 12.0.

\section{RESULTS}

The distribution of allelic and genotypic frequencies of DRD3 Ser9Gly and COMT rs 165656 in patients and controls are summarized in Table 1 . The genotype distribution of the polymorphism DRD3 Ser9Gly was in HWE for patients $(\mathrm{P}=0.1251)$ and deviated from HWE for controls $(\mathrm{P}=0.0137)$. However, there is a significant difference in the genotype distribution of the polymorphism COMT rs165656, which was out of HWE for both patients and controls $(\mathrm{P}=0.0000)$.

There was no significant difference between the two groups regarding the allelic distribution $\left[\chi^{2}=0.003\right.$; d.f. $\left.=1 ; \mathrm{P}=0.930 ; \mathrm{OR}=1.015(95 \% \mathrm{CI}=0.566-1.821)\right]$. The genotype distribution between patients and controls was analyzed $\left(\chi^{2}=4.155\right.$; d.f. $\left.=2 ; \mathrm{P}=0.125\right)$ and found to have no significantly different trend. In addition, no significant trend for an excess of Gly-containing genotype (Ser/Gly and Gly/Gly) was observed in patients compared with 


\begin{tabular}{|c|c|c|c|c|c|c|}
\hline \multirow[t]{2}{*}{ SNPs } & \multicolumn{2}{|c|}{ Allele (\%) } & \multicolumn{3}{|c|}{ Genotype (\%) } & \multirow[t]{2}{*}{ HWE P-value } \\
\hline & Ser & Gly & Ser/Ser & Ser/Gly & Gly/Gly & \\
\hline \multicolumn{7}{|l|}{ DRD3 } \\
\hline Patients & $347(66.5)$ & $175(33.5)$ & $120(46.0)$ & $107(41.0)$ & $34(13.0)$ & 0.1251 \\
\hline Controls & $284(65.7)$ & $148(34.3)$ & 84 (38.9) & $116(57.7)$ & $16(7.4)$ & $0.0137^{*}$ \\
\hline Chi-square (d.f.) & $0.003(1)$ & & $4.155(2)$ & & & \\
\hline $\mathrm{P}$ & 0.960 & & 0.125 & & & \\
\hline OR $(95 \% \mathrm{CI})$ & $1.015(0.566-1.821)$ & & & & & \\
\hline COMT & G & $\mathrm{C}$ & GG & $\mathrm{GC}$ & $\mathrm{CC}$ & \\
\hline Patients & $325(62.3)$ & $197(37.7)$ & $73(22.7)$ & $179(68.6)$ & $9(3.4)$ & $0.0000^{*}$ \\
\hline Controls & $282(65.3)$ & $150(34.7)$ & $70(32.4)$ & $142(65.7)$ & $4(1.8)$ & $0.0000^{*}$ \\
\hline Chi-square (d.f.) & $0.194(1)$ & & $0.533(2)$ & & & \\
\hline $\mathrm{P}$ & 0.659 & & 0.766 & & & \\
\hline OR $(95 \% \mathrm{CI})$ & $0.879(0.494-1.563)$ & & & & & \\
\hline
\end{tabular}

SNPs = single nucleotide polymorphisms; DRD3 = dopamine D3 receptor; COMT = cathechol-o-methyltransferase; $\mathrm{HWE}=$ Hardy-Weinberg equilibrium; d.f. $=$ degrees of freedom; $\mathrm{OR}=$ odds ratio; $95 \% \mathrm{CI}=$ confidence interval at $95 \%$.

controls $\left[\chi^{2}=1.003\right.$; d.f. $\left.=1 ; \mathrm{P}=0.317 ; \mathrm{OR}=0.751(95 \% \mathrm{CI}=0.428-1.317)\right]$. Besides, there was no evidence that Ser9Gly homozygosity served as a risk factor for SCZ $\left[\chi^{2}=3.388\right.$; d.f. $=$ $1 ; \mathrm{P}=0.066 ; \mathrm{OR}=1.689(95 \% \mathrm{CI}=0.965-2.957)]$.

In term of rs 165656 , allele frequencies for patient did not deviate significantly from controls $(\mathrm{P}=0.659 ; \mathrm{OR}=0.879 ; 95 \% \mathrm{CI}=0.494-1.563)$. The genotype frequencies also lacked association $\left(\chi^{2}=0.533, \mathrm{P}=0.766\right)$ with SCZ. There was also no evidence of association between homozygosity $\left[\chi^{2}=0.205\right.$; d.f. $\left.=1 ; \mathrm{P}=0.651 ; \mathrm{OR}=0.872(95 \% \mathrm{CI}=0.482-1.577)\right]$ and the G-containing genotype $\left[\chi^{2}=0.205\right.$; d.f. $=1 ; \mathrm{P}=0.652$; OR $=0.660(95 \% \mathrm{CI}=0.108$ 4.036)] for patients and controls with SCZ.

\section{DISCUSSION}

The results of the current case-control study suggested a lack of difference in genotype distribution of DRD3 Ser9Gly between patients and controls. This is in partial agreement with several case-control studies conducted among Asians and Caucasians. Hoogendoorn et al. (2005), Chang et al. (2007) and Fathalli et al. (2008) suggested a negative association between allelic and genotype distributions and SCZ, while Utsunomiya et al. (2008) found statistically significant evidence of such an association.

Our inability to detect an association between homozygosity of DRD3 Ser9Gly and SCZ, as demonstrated in more homogenous Caucasian populations (Crocq et al., 1992; Jonsson et al., 2003) may be due to genetic heterogeneity of the Malay population. Fathalli et al. (2008) reported a lack of association between homozygosity and SCZ in Caucasians recruited from different countries. The issue of population stratification cannot be excluded even in the Japanese, which is considered to be a more homogenous ethnic group (Utsunomiya et al., 2008).

COMT encodes an enzyme involved in the metabolism of dopamine and maps to a commonly deleted region that increases schizophrenia risk (De Luca et al., 2006). The inconsistent results from the association study of allele and genotype with $\mathrm{SCZ}$ might be also due to the genetic variability of the COMT gene. Zhang et al. (2007) indicated that the G allele and GG genotype rs 165656 are significantly associated with mental retardation, which is closely related to psychotic disorders. Our results showed that there was no significant difference 
between patients and controls by allele or genotype status. In our study, the CC genotype is rare in the patients, but the $\mathrm{C}$ allele frequency is higher in patients compared to controls. The non-associative relationship between rs 165656 and SCZ was supported by Pal et al. (2009).

In Malaysia, ethnicity measures identity rather than origin and ancestry. Immigrants from the Indonesian Archipelago have been absorbed into the Malay community (Nagaraj et al., 2008). Thus, the measurement by self-identification suggested the possibility of a population who may contribute to a false-positive and/or false-negative identifications (Schulze and McMahon, 2002). Despite the limitation of ethnicity, this has merit in terms of clinical diagnosis. We can rule out other confounding factors, such as different diagnostic tools or the use of inpatients or outpatients. All schizophrenic subjects were inpatients from one psychiatric hospital (Hospital Bahagia, Ulu Kinta) and clinical records were complete.

Although our results are inconclusive in determining an association between DRD3 Ser9Gly and COMT rs165656 polymorphisms and SCZ, these genes cannot be excluded from having an implication in SCZ. Talkowski et al. (2006) reported that Ser9Gly polymorphism was associated with $\mathrm{SCZ}$ only when it was present in a common haplotype spanning intron 1 to the 3' region of DRD3 gene and not when it was present in other haplotypes. Thus, further studies with linked variants for this region may contribute to SCZ susceptibility.

\section{ACKNOWLEDGMENTS}

Research supported by the Ministry of Higher Education (MOHE), Malaysia, under Fundamental Research Grant Scheme, FRGS (\#4403/L02) and the Universiti Tunku Abdul Rahman (UTAR) Research Grant (\#6200/L02 and \#6202/T02). We are very grateful to Dato’ Dr. Suarn Singh Jasmit Singh, Director and Senior psychiatrist of Ulu Kinta Hospital Bahagia and also all other psychiatrists (Yee Chuang Cheah, Rabaiah Mohd Salleh, Tak Wah Loo, Raziffah Abdul Rahman, Satnam Kaur Harbhajan Singh, Zulkifri Ghaus, Ahmad Syukri Chew Abdullah, Bilbir Kaur Chigara Singh) who participated in patient diagnosis and blood sample collection.

\section{REFERENCES}

Chang HA, Lu RB, Lin WW, Chang CC, et al. (2007). Lack of association between dopamine D3 receptor Ser9Gly polymorphism and schizophrenia in Han Chinese population. Acta Neuropsychiatr. 19: 344-350.

Chen J, Lipska BK, Halim N, Ma QD, et al. (2004). Functional analysis of genetic variation in catechol-o-methyltransferase (COMT): effects on mRNA, protein, and enzyme activity in postmortem human brain. Am. J. Hum. Genet. 75: 807-821.

Crocq MA, Mant R, Asherson P, Williams J, et al. (1992). Association between schizophrenia and homozygosity at the dopamine D3 receptor gene. J. Med. Genet. 29: 858-860.

De Luca V, Tharmalingam S, Müller DJ, Wong G, et al. (2006). Gene-gene interaction between MAOA and COMT in suicidal behavior: analysis in schizophrenia. Brain Res. 1097: 26-30.

Durany N, Thome J, Palomo A, Foley P, et al. (1996). Homozygosity at the dopamine D3 receptor gene in schizophrenic patients. Neurosci. Lett. 220: 151-154.

Ebstein RP, Macciardi F, Heresco-Levi U, Serretti A, et al. (1997). Evidence for an association between the dopamine D3 receptor gene DRD3 and schizophrenia. Hum. Hered. 47: 6-16.

Fathalli F, Rouleau GA, Xiong L, Tabbane K, et al. (2008). No association between the DRD3 Ser9Gly polymorphism and schizophrenia. Schizophr. Res. 98: 98-104.

Hoogendoorn ML, Bakker SC, Schnack HG, Selten JP, et al. (2005). No association between 12 dopaminergic genes and schizophrenia in a large Dutch sample. Am. J. Med. Genet. B. Neuropsychiatr. Genet. 134B: 6-9.

Ioannidis JP, Ntzani EE, Trikalinos TA and Contopoulos-Ioannidis DG (2001). Replication validity of genetic association studies. Nat. Genet. 29: 306-309.

Jonsson EG, Flyckt L, Burgert E, Crocq MA, et al. (2003). Dopamine D3 receptor gene Ser9Gly variant and schizophrenia: 
association study and meta-analysis. Psychiatr. Genet. 13: 1-12.

Jonsson EG, Kaiser R, Brockmoller J, Nimgaonkar VL, et al. (2004). Meta-analysis of the dopamine D3 receptor gene (DRD3) Ser9Gly variant and schizophrenia. Psychiatr. Genet. 14: 9-12.

Kunugi H, Vallada HP, Hoda F, Kirov G, et al. (1997). No evidence for an association of affective disorders with high- or low-activity allele of catechol-o-methyltransferase gene. Biol. Psychiatry. 42: 282-285.

Lannfelt L, Sokoloff P, Martres MP, Pilon C, et al. (1992). Amino acid substitution in the dopamine D3 receptor as a useful polymorphism for investigating psychiatric disorders. Psychiatr. Genet. 2: 249-252.

Le Coniat M, Sokoloff P, Hillion J, Martres MP, et al. (1991). Chromosomal localization of the human D3 dopamine receptor gene. Hum. Genet. 87: 618-620.

Nagaraj S, Lee KH, Tey NP and Ng CW (2008). Counting and Integration: The Experience of Malaysia, Working Paper Series, No 2008-3. Faculty of Economics and Administration, University of Malaya, Malaya.

National Mental Health Registry Report (2003-2005). Department of Psychiatric and Mental Health, Hospital Kuala Lumpur, National Mental Health Registry, Kuala Lumpur.

Pal P, Mihanovic M, Molnar S, Xi H, et al. (2009). Association of tagging single nucleotide polymorphisms on 8 candidate genes in dopaminergic pathway with schizophrenia in Croatian population. Croat. Med. J. 50: 361-369.

Scharfetter J, Chaudhry HR, Hornik K, Fuchs K, et al. (1999). Dopamine D3 receptor gene polymorphism and response to clozapine in schizophrenic Pakistani patients. Eur. Neuropsychopharmacol. 10: 17-20.

Schulze TG and McMahon FJ (2002). Genetic association mapping at the crossroads: which test and why? Overview and practical guidelines. Am. J. Med. Genet. 114: 1-11.

Schwab SG and Wildenauer DB (2008). Research on causes for schizophrenia: are we close? Schizophr. Res. 102: 29-30.

Shifman S, Bronstein M, Sternfeld M, Pisante A, et al. (2004). COMT: a common susceptibility gene in bipolar disorder and schizophrenia. Am. J. Med. Genet. B. Neuropsychiatr. Genet. 128B: 61-64.

Spurlock G, Williams J, McGuffin P, Aschauer HN, et al. (1998). European multicentre association study of schizophrenia: a study of the DRD2 Ser311Cys and DRD3 Ser9Gly polymorphisms. Am. J. Med. Genet. 81: 24-28.

Staddon S, Arranz MJ, Mancama D, Perez-Nievas F, et al. (2005). Association between dopamine D3 receptor gene polymorphisms and schizophrenia in an isolate population. Schizophr. Res. 73: 49-54.

Suzuki M, Hurd YL, Sokoloff P, Schwartz JC, et al. (1998). D3 dopamine receptor mRNA is widely expressed in the human brain. Brain Res. 779: 58-74.

Talkowski ME, Mansour H, Chowdari KV, Wood J, et al. (2006). Novel, replicated associations between dopamine D3 receptor gene polymorphisms and schizophrenia in two independent samples. Biol. Psychiatry 60: 570-577.

Tenhunen J, Salminen M, Lundstrom K, Kiviluoto T, et al. (1994). Genomic organization of the human catechol-omethyltransferase gene and its expression from two distinct promoters. Eur. J. Biochem. 223: 1049-1059.

Utsunomiya K, Shinkai T, De Luca V, Hwang R, et al. (2008). Genetic association between the dopamine D3 gene polymorphism (Ser9Gly) and schizophrenia in Japanese populations: evidence from a case-control study and metaanalysis. Neurosci. Lett. 444: 161-165.

Zhang K, Gao J, An C, Gao X, et al. (2007). An association study between cathechol-o-methyltransferase gene and mental retardation in the Chinese Han population. Neurosci. Lett. 419: 83-87. 